\title{
STUDY OF FEATURES OF ECONOMIC COMPETITION AT WORLD MARKETS OF FOOD AND AGRICULTURAL RAW MATERIALS IN THE CONTEXT OF FOOD SAFETY PROVISION
}

\author{
Iryna Karp \\ Ternopil National Economic University \\ 11 Lvivska str., Ternopil, Ukraine, 46000 \\ karp.zubel@gmail.com \\ Igor Gonak \\ Department of International Economics \\ Ternopil National Economic University \\ 11 Lvivska str., Ternopil, Ukraine, 46000 \\ gogrya@gmail.com
}

\begin{abstract}
Changes that take place in XXI century in the European economy cause not only the decrease of the topicality of problems of food safety provision, but condition their global and large-scale character. The question of people provision with food products, overcoming of poverty, economic competition at world markets of food and agricultural raw materials is for today priority for the whole international community. This problematic has different aspects and manifestation forms in different countries, regions, territories. The geography of products provision has an ambiguous character: a loss of products and their high quality is observed in certain regions, whereas other regions suffer from malnutrition and low-quality food products. The important role is plaid there by losses of society from waste of food products and low-quality competition, caused by different socio-political and socio-economic interests of countries and desire to influence the internal life of other countries through influence mechanisms on their food market functioning. In general food resources are enough throughout the world for providing satisfactory nutrition of the whole mankind. But food production it is not always provided where it is needed. Starvation and malnutrition, impoverishment of almost $1 / 5$ of the population of the planet is the main social content of the food crisis. The economic competition at world food and agricultural raw materials markets plays no less important role. World tendencies of the value conjuncture, insufficient attention of state leaders to accumulation of sufficient resources for providing parity in the global economic competition create threats in providing food safety of many countries.

Keywords: market of food and agricultural raw materials, economic competition, food safety, malnutrition, lack of drinking water, "achievement of hungry goal", losses and waste of food products.

\section{Introduction}

The effective and fruitful production of agricultural products is a base for providing food safety of a state. Food and agricultural raw materials have been always the most important economic and social resource, which control provoked confrontations in history. Countries that possessed food resources always had an additional advantage in economic and political competition. Tendencies of economic competition at world markets of food and agricultural raw materials have a great influence on the international economy. At the beginning of the third millennium countries use indirect economic methods and means of influence for getting certain positions and keeping them at markets of food and agricultural raw materials more and more often. The question of the effective development of the agricultural sector, insufficient attention from the state to problems of provision with food products create conditions for threats in human provision with food.
\end{abstract}

\section{Analysis of literary data and statement of the problem}

Famous scientists devoted their works to the study of separate aspects of functioning of markets of food and agricultural raw materials, features of development and functioning of world markets of food products, problems of food safety provision. 
Thus, the analysis of theoretical and applied aspects of functioning of markets of food and agricultural raw materials was realized in the article. There was characterized the influence of STP achievements on agricultural production [1]. There was considered the influence of political instability and conflicts on unsatisfactory provision of poorest countries of Near East and Northern Africa with food. It was proved, that the number of people starving because of an instable condition of food safety grows each time [2]. There was assessed the problematic of provision of food safety of countries that have achieved goals of millennium development and ones of the world food summit. There was studied the question of the population growth, child malnutrition, drinking water lack [3]. There was elaborated the theme of problems of regulation of losses and waste of food products, consumed by a human. There was traced the dependence between insufficiency of resources and low productivity of food products [4]. There were analyzed special features of agricultural products realization for export. There were studied growth rates of export of agricultural raw materials [5]. There was analyzed the influence of food safety and other factors on recreating processes at geopolitical and geoeconomic levels. There was analyzed the influence of food safety on the character of modern international economic processes as to production and consumption of food and agricultural raw materials. There was proved the urgency in relations, conditioned by external and internal policy, realized by interested countries, political blocs, intergovernmental and regional associations [6]. But these studies may not be considered as comprehensive, this theme needs the additional elaboration.

\section{Aim and tasks of research}

The aim of the article is the determination of possibilities of providing food safety at world markets of food and agricultural raw materials as a combination of informational, legal political and economic mechanisms.

The following tasks were set for attaining this aim:

1. To study closeness of connections between the international economy and the market of food and agricultural raw materials.

2. To analyze the influence of political instability and conflict on food safety provision in countries of Near East and Northern Africa.

3. To outline possibilities of overcoming problems of agricultural nature management and production of food goods, faced by the international community.

\section{Materials and methods of research}

The methodological base of the study is the dialectical method of scientific cognition. General scientific and special methods were used during the study, among them the most essential are: the abstract-logic method - for formulating research conclusions; methods of analysis, synthesis and generalization - for studying bases of features of economic competition for providing food safety at the world market of food and agricultural raw materials.

\section{Results of research}

At the turning point of millenniums the international economy faced principally new problems of provision, use, results of processing and consumption of food. Annual modern world consumption of food is more than 9 trl dol or near $18 \%$ of all annual costs of consumers [7]. The use of agricultural raw materials is growing under conditions of the continuous growth of the planet population number that will grow up to 9,6 bil persons, according to UNO prognoses [8] and production volumes will grow by $70 \%$ [9].

The problem of production and consumption of food and agricultural raw materials and its solutions are in the focus of the economic policy. Food and agricultural raw materials are the main natural material paradigm of human life activity and is a subject of both international socio-economic cooperation and geopolitical and geoeconomic competition [6].

Quantitatively limited production of food and agricultural raw materials conditions certain features of their use, connected with: global climate changes, great resource consumption of products; technical impossibility of their unlimited involvement into processing and consumption; 
chemical, radioactive, biological and other pollution of agricultural soils; inequality of possibilities of production of rough food resources of separate continents, regions and countries; ecological and geographic limits of the possible augmentation of volumes of production and processing of rough food resources; continuous growth of the planet population; presence of different political and economic intents of economic blocs and separate countries that can undertake actions, contradictory to the socio-economic, socio-political and historical logic; taking territories out of agricultural circulation by spreading of deserts (especially, Sahara in Africa). These factors play the determinative role as to recreating processes at geopolitical and geoeconomic levels as to production and consumption of food and agricultural raw materials. These relations often reach urgency, conditioned by the external and internal policy, realized by interested countries, political blocs, intergovernmental and regional associations [6].

Attention must be paid to problems of insufficiency of food products provision to most vulnerable regions of Near East and North Africa - NENA. Just here the level of poverty and malnutrition is the highest comparing with other regions. The situation in these countries underwent essential changes taking into account intensification of conflicts and political instability. There was not achieved the decrease of the absolute number of starving people within the context of realization of Millennium Development Goal MDG. In NENA region the number of chronically starving persons increased twice from 16,5 mln in 1990-1992 to $33 \mathrm{mln}$ in 2014-2016. At the same time the situation in subregions is different. The insufficient decrease of the malnutrition condition is typical for countries of Persian Gulf Cooperation Council (GCC) and Yemen. But the number of persons, starving because of the unstable condition of food safety, caused by conflicts and high poverty level, increased.

Last years the most populated subregion Mashreq (Egypt, Iraq, Iran (Islamic Republic), Jordan, Lebanon, Sudan and Syria) in NENA demonstrated the abrupt increase of malnutrition spread from the level of $5 \%$ in 1990-1992 to more than $8 \%$. The number of starving people (near $23 \mathrm{mln}$ ) in the subregion is $70 \%$ of starving persons in the region. In the subregion Maghreb - Algeria, Libya, Mauritania, Morocco and Tunisia the number of starving people essentially decreased. It is also the single region that achieved the "Hungry goal".

The crisis in Syria caused the fact that among 13,6 mln persons - 9,8 mln ones in Syria and 3,8 mln refugees need food help. The number of starving people in Iraq increased from $8 \%$ in 1990-1992 to $23 \%$ in 2014-2016. Each forth dweller of Yemen is considered as a starving one.

Within NENA region countries positions by malnutrition level are different. In 1990-1992 15 of 19 countries achieved the "hungry goal" of MDG: Algeria, Bahrain, Egypt, Iran (Islamic Republic), Jordan, Kuwait, Lebanon, Libya, Mauritania, Morocco, Oman, Qatar, Saudi Arabia, Tunisia and United Arab Emirates. Among them only Kuwait and Oman also achieved the goal of WFS (World Food Summit). Algeria and Tunisia are very close to achieving this goal. The essential progress is also observed in Mauritania, where the spread of malnutrition decreased from $15 \%$ in 1990-1992 to $6 \%$ in 2014-2016. Table 1 presents NENA countries that achieved goals of malnutrition overcoming.

Table 1

NENA countries that achieved goals of malnutrition overcoming

Countries that achieved both millennium development goals and goals of world food summit

Kuwait, Oman
Countries that achieved millennium development goals

Algeria, Bahrain, Egypt, Iran (Islamic Republic), Jordan, Kuwait, Lebanon, Libya, Mauritania, Morocco, Oman, Qatar, Saudi Arabia, Tunisia and United Arab Emirates

Source: Created by the authors based on [3]

The subregion is supplied with food products mainly at the expanse of their import. Mean volumes of food goods consumption in the region increased from $2916 \mathrm{kcal} / \mathrm{person} /$ day in 1990-1992 to $3214 \mathrm{kcal} /$ person/day in 2014-2016. Such level is essentially higher than the mean world in- 
dex - $2902 \mathrm{kcal} /$ person/day. Crop plants and other products, rich with carbohydrates, are the main ration source of this region. Despite the high import dependence, this region achieved the essential progress in increasing own supplying. For example, crop plants production grows approximately by $4,3 \%$ annually, although corn productivity remains lower the mean world level. At the same time food production permanently remains behind the necessary demand that causes the fast growth of import. The growth of needs in nutrition and limited internal supplying base also made NENA the greatest netto-importer of corn plants in the world, moreover, more than a half of corn plants consumption is realized from other regions.

Existent programs of social protection, introduced by governments of the region played the certain role in decreasing poverty and improving an access to food. But universal subsidies for food products and fuel turned to be ineffective, but they are directed not only on satisfying needs of poor people. Separate subsidies for food products negatively influenced also the quality of nutrition of poor households. Although programs of social protection, favored the increase of the level of poor people's access to food and improvement of the food situation, the faster human progress needs the strengthening of such arrangement that would favor an access to food products, especially for poor population layers.

Despite the decrease of the poor population number in separate regions, the mean value of index exceeds $10 \%$. It is for example, Egypt, Mauritania, Sudan, Tunisia and Yemen.

Starting from $90-\mathrm{s}$, there was achieved the essential progress in the decrease of child chronic malnutrition, especially, in Mauritania - from $55 \%$ in 1990 to $22 \%$ in, 2012, Tunisia - from $31 \%$ in 1990 to $10 \%$ in 2012, Morocco - from $30 \%$ in 1994 to $15 \%$ in 2011, Oman - from $26 \%$ in 1991 to $10 \%$ in 2009. At the same time almost a fourth of the population suffers from obesity, making this region the largest one with obesity. Such index twice exceeds the mean world one and is almost trice more than in developing countries. The deficiency of important microelements in the organism is the main indicator than results in obesity in both rich and poorer countries.

The demographic situation management is among priorities in NENA region. The population growth in the region is characterized with high rates - near $2 \%$ annually comparing with the mean world one $-1,2 \%$ in 2010-2016. The region population is estimated approximately as $400 \mathrm{mln}$, up to $600 \mathrm{mln}$ are expected till 2050. The population growth together with intensification of urbanization and change of consumption models will in future results in the increase of demand for food products and decrease of soils, suitable for agriculture. It is expected that the policy of family planning will be the most effective way of decreasing population growth rates and may result in improving socio-economic condition of households. Some arrangements like these have already proved their effectiveness in such countries as Nigeria, Egypt, Iran, Lebanon, Liberia, Morocco and Tunisia. An access to land, technologies and some types of credits is extremely important in this region, especially for rural youth and women; in another case they are not protected.

NENA region is the one of most suffering ones from the lack of drinking fresh water. Incomings of renewed water for one person decreased by two thirds last 50 years, and now are $10 \%$ of the world average one, despite the fact that this region has invested much in irrigation during many years [10]. More than $80 \%$ of accessible water resources are used for agricultural needs, but there are essential differences between subregions. In Mashreq countries the part of irrigated soils reaches $43 \%$ of the whole area of agricultural lands. Maghrib countries depend on irrigation much less (7-18 \%), whereas Egypt is irrigated in almost $100 \%$. The use of indirect subsidy for irrigating water is the common policy in this region.

Food products losses are the essential problem for this region. According to estimations, $34 \%$ of food products, suitable for human consumption are wasted or lost [4]. Such level of waste and losses is extremely inadmissible in the region that depends on international markets to satisfy needs in food to such extent. Taking into account the limited resource base of the region and the low productivity of food products, high losses in food are not only uneconomic, but ecologically fatal and destructive for providing food safety. The decrease of FLW (food loss and waste) needs essential additional investments in the limited power of saving the region. This problem expresses itself mostly in food products storage and also in the ability to process corn plants. In several countries of the region most farmers store their corns in traditional conditions, so most losses are caused by 
different types of rodents, insects and birds. For example, Egypt loses 13-15\% of accessible corns between harvesting and final consumption. High waste and losses of perishable products, especially, fruits and vegetables, limit the ability of countries of this region to export their excess (Table 2).

Table 2

Estimation of losses of food products in several fruits and vegetables in the countries of NENA region

\begin{tabular}{ccc}
\hline Country & Product name & Estimation of losses (\%) \\
\hline & Fresh fruits & 19 \\
Egypt & Fresh vegetables & 29 \\
& Oranges & 14 \\
Iran & Tomatoes & 15 \\
& Grape & 13 \\
Jordan & Eggplant & 19 \\
& Tomatoes & 18 \\
Oman & Fruits and vegetables & $3-19$ \\
Saudi Arabia & Cucumbers, dates, grape, tomatoes & $15-23$
\end{tabular}

Source: Created by the author based on [2]

The key moment of food safety provision is animal husbandry, because, high incomes, fast population growth, urbanization and change of consumption models favored the abrupt increase of demand for animal products in this region in last decades. NENA region has 98 mln units of animal husbandries, $80 \%$ of which are concentrated only in six countries: Algeria, Egypt, Iran, Mauritania, Morocco and Sudan. The region in whole is a pure importer of animals, products of animal origin and forage. The problems for the further development of animal husbandry are periodical droughts, desertification, degradation of pastures that worsen with climate changes, conflicts and long-term crises.

The successive development of the world economic system results in the fast development and growth of the world market of food and agricultural raw materials. At that it is influenced by the essential number of diverse factors. It influences international economic and socio-political processes. World trade of food and agricultural raw materials is determined by the following peculiarities for today:

- demand and supply of agricultural raw materials and products of its processing depends at such international level on a geoeconomic and geopolitical situation, climate conditions, quantity of land in the agricultural circulation, developed international transport infrastructure of countries-exporters and countries-importers. So, the high turbulence and volatility at the world market is typical for such trade;

- prices at such markets are subject to essential fluctuations that are difficult to prognosticate. Peculiarities of price-creation of agricultural raw materials and products at the world market are connected with: the influence of the external trade policy of states and economic associations; price volatility; competitive influence of supply of synthetic and artificial surrogates; prices for such goods are oriented on auction and exchange ones; there is the plurality of prices, connected with the diversity of trade centers, sorts, discord in delivery terms;

- there is observed the long-term exceed of supply of food and agricultural raw materials over demand for it. Food and agricultural raw materials supply increases at decreasing costs for them in the world economy as a result of introducing scientific-technical innovations. There takes place the active shortening of the number of economically developed world countries, engaged in agriculture - in the last half of the century the number of people, worked in the agricultural field decreased 5 times [1]. So, such situation at the international food and agricultural market has the long-term dynamics of prices decrease and conditions additional risks of increasing the number of economic crises in countries that are active exporters of these goods (countries with the narrow nomenclature of export of food and agricultural raw materials and products of its processing), because export of food and agricultural raw materials and products of its processing provides the main part of incomes from economic activity for these countries; 
- countries-partners aim to establish long-term relations, based on long-term international agreements, which guarantee sales of food, agricultural raw materials and products of its processing for a long period for a country-exporter; and an importer will receive possibilities of guaranteed regular deliveries of food, agricultural raw materials and products of its processing with fixed or well prognosticated prices (long-term contracts take near $30 \%$ of the world raw materials export [5]);

- trade of food, agricultural raw materials and products of its processing is closely connected with provision of other good types, and is a part of commercial operations, complicated types of external economic cooperation, large-scale agreements on a compensation basis;

- the essential imbalance exists at the world materials market - growth rates of trade of fuel-energetic resources and mineral raw materials exceeds growth rates of trade of food and agricultural raw materials;

- there is observed the high level of monopolization at markets of food and agricultural raw materials. Transnational corporations and great national producers, specialized on production of food and products of agricultural raw materials processing, have a possibility to fix monopoly low prices for buying raw materials and high prices for semi-products or ready products (at that internal corporative deliveries of agricultural raw materials are realized for lowered transfer prices for decreasing tax load and optimizing costs);

- limits of influence and intervention of subject that have no direct relation to trade of food, agricultural raw materials and products of its processing in determination of volumes, directions, forms and methods of trade of food, agricultural raw materials and products of its processing, grow;

- there is observed the continuous growth of requirements of importers of food, agricultural raw materials and products of its processing to the quality and ecological safety of food goods;

- volumes of trade of ready products and semi-products, manufactured on the base of agricultural raw materials actively grow; growth rates of export of agricultural raw materials decrease at the absolute increase of volumes of trade of this goods group [5].

Transformations that take place at the world map of production of food and agricultural raw materials are closely connected with changes on it. The mutual influence is traced there. The desire to control volumes of production of realization of food and agricultural raw materials by countries-exporters results in intensification of economic competition and essential price fluctuations for resources, in socio-political competition, military confrontations and altering of boundaries and other geopolitical events. Different socio-economic events in importers and exporters of food and agricultural raw materials influence the price dynamics differently. For example, negative socio-economic events in countries-importers condition the decrease of their economic growth rates, and world prices of food and agricultural raw materials decrease, and the economic increment in countries-importers provides the growth of international prices of food and agricultural raw materials at world markets. And on the contrary, chaos in the socio-political and economic life of countries-exporters of food and agricultural raw materials conditions the growth of prices of food and agricultural raw materials because of a possible or actual deficit of food and agricultural raw materials at the world food market, and the internal political and socio-economic stability in these countries conditions the descendent price dynamics of food and agricultural raw materials.

Exporters and importers of food and agricultural raw materials use different methods of influencing the market of food and agricultural raw materials, providing food safety in the world, especially in separate most vulnerable regions.

Countries-exporters express their interest not only in increasing production of food and agricultural raw materials, but in realization of products of agricultural raw materials processing (for example, sunflower oil instead of sunflower seeds), creating new working places and providing the growth of an income part of a budget. At the same time, countries-importers demonstrate their interest in processing raw materials resources at the custom territory of their own country and to consume and export ready products, produced by internal producers, increasing the national wealth of own economies. In this connection countries-importers use the following methods of attaining their aim because of the growth of economic competition:

- use tariff and non-tariff methods of protection of the internal market from the external economic expansion, non-prohibited by GATT-WTO; stimulate socio-economic destabilization 
in countries-exporters of food and agricultural raw materials, interfering introduction of scientific-technical progress and effective projects on processing of food and agricultural raw materials, and provoke the growth of costs for national safety;

- realize the state economic policy in the sphere of the effective economic stimulation for creating high-effective profitable enterprises for processing food and agricultural raw materials and outputting products with a high part of added value;

- guarantee the acceptance of legislative initiatives as to raising ecological normative and quality standards for semi-products and ready products, produced of agricultural raw materials;

- give short-term credits with a low interest rate to economic subjects (country and firms) of countries-exporters, intending to draw them in "debt kabala" for washing of financial resources and decreasing perspectives of the economic development of countries-exporters of food and agricultural raw materials - economic subjects of a country-exporter often cover their debt obligations immediately after receiving export earnings from raw material resources, instead of financing investments in production of ready products;

- use exchange players for influencing the price dynamics of food and agricultural raw materials at world markets.

Countries-exporters of food and agricultural raw materials, intended to create new working places and maximize profits of national commodity producers and tax incomes, use different influence ways on markets of food and agricultural raw materials, on food safety provision:

- embody cartel compacts, intending to provide the prices growth and maximize profits of enterprises-exporters, provoking creation of the artificial deficit of such goods at the world market, decreasing volumes of their realization for export;

- realize cartel compacts, intending to decrease prices for the growth of food and agricultural raw materials export at world markets. It may be realized for: raising demand for food raw materials and other agricultural resources at world markets and providing the international economy increment that will result in the growth of incomes of internal producers of countries-exporters of food and agricultural raw materials; decreasing investment attractiveness of production of food and agricultural products with a high cost price in other countries (for example, planting products in droughty regions or other regions with frequent weather changes: hurricanes, tornado, tsunami, excessive quantity of precipitation);

- individual augmentation of production and realization of food and agricultural raw materials by several countries-exporters for receiving an additional part of the world market of food and agricultural raw materials;

- stimulation of redistribution of economic resources, received from realization of food and agricultural raw materials for export, from "eating away" to the economic growth of the internal economy: stimulation of formation of national firms for processing rough food resources and agricultural raw materials for producing goods with more added value and export of semi-products and ready products (sunflower oil, cheeses); investments of incomes, received from export of food and agricultural raw materials, in high-effective and high-tech economic spheres - machine- and shipbuilding, production of energy-efficient technologies, electrotechnical, cosmic, agrarian, defensive, pharmaceutical and other fields).

It may be summarized, that financial incomes, received from realization of food and agricultural raw materials, may not only stimulate the international economic growth, increase of the national wealth of countries-exporters by creating reserve funds of incomes from export of food and agricultural raw materials and condition other positive results, but cause the socio-economic, political and military destabilization in the world and disintegration of separate countries that create additional risks for world food safety.

\section{Discussion of research results}

The main advantage of this research is the attempt to characterize peculiarities of economic competition at world markets of food and agricultural raw materials in the context of food safety provision. But this theme is difficult and needs more large-scale and detail researches. 
This research is useful for effective planning of food safety at the state level under conditions of chaotic changes at world markets of food and agricultural raw materials.

This research is not a continuation of previous ones that is why the authors plan to work further for improving it in future.

\section{Conclusions}

1. It may be stated, that the international economy and world markets of food and agricultural raw materials are extremely closely connected between each other. Negative socio-economic events in countries-importers condition the decrease of their socio-economic growth rates, and world prices of food and agricultural raw materials decrease, and the economic increment in countries-importers provides the growth of international prices of food and agricultural raw materials at world markets. And on the contrary, instability in the socio-economic life of countries-exporters of food and agricultural raw materials conditions the growth of these resources because of a deficit of food and agricultural raw materials at the world market, and the internal socio-economic stability in these countries conditions the descendent price dynamics of food and agricultural raw materials.

2. It was proved, that countries of Near east and Northern Africa are the most vulnerable to political instability and international conflicts that directly influence the sufficient food safety level (just in these countries most losses and waste of food are traced).

3. Despite the difficultness of problems of agricultural nature management and production of food goods, faced by the international economy, a possibility of overcoming them exists. But to realize it, it is necessary to threat agricultural resources that are the wealth of not only a separate country, but also international community, responsibly.

\section{References}

[1] Mamaluj, O. O., Grycenko, O. A., Gryshhenko, L. V., Darnopyh, G. Yu. (2003). Osnovy ekonomichnoyi teoriyi. Kyiv: Yurinkom Inter, 480.

[2] Food and Agriculture Organization (2015). Report of the expert consultation Meeting on Food losses and Waste Reduction in the near east Region. Available at: http://www.fao.org/

[3] Regional Overview of Food Insecurity Near East and North Africa (2015). 32. Available at: www.fao.org/3/a-i4644e

[4] Food and Agriculture Organization (2016) Global food losses and food waste - extent, causes and prevention. Rome, 37. Available at: http://www.fao.org/docrep/014/mb060e/mb060e.pdf

[5] Kozak, Yu. G., Logvynova, N. S., Rzhepishevsko, K. I. (2005). Osnovy mizhnarodnoyi torgivli. Kyiv: Centr navchalnoyi literatury, 656.

[6] Novyczkyj, V. Ye. (2003). Mizhnarodna ekonomichna diyalnist Ukrayiny. Kiev: KNEU, 948.

[7] Food, beverage and agriculture industry in sights. Available at: http://www.gecapital.com.au/ knowledge-hub/2014/food-and-beverage-industry/food-beverage-and-agriculture-industry-insights.pdf

[8] Oficijnyj sajt OON. Available at: http://www.un.org

[9] World trade report 2014 (2014). Available at: https://www.wto.org/english/res_e/booksp_e/ world_trade_report14_e.pdf

[10] United nations, department of economic and social affairs - Population division, 2015 (2015). Available at: http://www.un.org/en/development/desa/population/ 